\title{
A reactive mitigation approach for managing supply disruption in a three-tier supply chain
}

Sanjoy Kumar Paul, Ruhul Sarker and Daryl Essam

\section{Abstract}

Corresponding email: sanjoy.ipe@gmail.com (S.K. Paul)

In this paper, we develop a quantitative reactive mitigation approach for managing supply disruption for a supply chain. We consider a three-tier supply chain system with multiple raw material suppliers, a single manufacturer and multiple retailers, where the system may face sudden disruption in its raw material supply. First, we develop a mathematical model that generates a recovery plan after the occurrence of a single disruption. Here, the objective is to minimize the total cost during the recovery time window while being subject to supply, capacity, demand, and delivery constraints. We develop an efficient heuristic to solve the model for a single disruption. Second, we also consider multiple disruptions, where a new disruption may or may not affect the recovery plans of earlier disruptions. We also develop a new dynamic mathematical and heuristic approach that is capable of dealing with multiple disruptions, after the occurrence of each disruption as a series, on a real-time basis. We compare the heuristic solutions with those obtained by a standard search algorithm for a set of randomly generated disruption test problems, which shows the consistent performance of our heuristic. Finally, a simulation model is developed to analyze the effect of randomly generated disruption events that are not known in advance. The numerical results and many random experiments are presented to explain the usefulness of the developed models and methodologies.

Keywords: Supply chain; supply disruption; reactive mitigation; recovery plan; mathematical model; quantitative approach; heuristic; simulation.

\section{Introduction}

In the modern business era, supply chains are an important part of many businesses. A manufacturing supply chain is a network which receives raw materials from suppliers as input, which it processes in manufacturing plants, to obtain final products for delivery to customers through a distribution network. A standard three-tier supply chain network consists of suppliers, manufacturers and retailers. Suppliers supply raw materials to manufacturers, and after processing in a manufacturing plant, final products are delivered to retailers according to their demand. In reality, a supply chain can face many uncontrollable problems, such as production and supply disruption (Sodhi \& Chopra 2004). Without a proper response to those problems, a supply chain system can be imbalanced, and an organization can consequently face huge financial loss, as well as loss of customer goodwill (Paul et al. 2016). 
Supply chain disruption management is an important research topic, as can be judged from the following examples. The first example is based on a survey conducted in 2011 by the Business Continuity Institute (Supply Chain Resilience, 2011), which reported that although awareness of supply chain risks is increasing, many companies remain exposed to high levels of risk. It found that $85 \%$ of survey respondents (from 550 organizations) experienced at least one disruption in their supply chains. It also stated that almost half of these businesses lost productivity, and incurred increased working costs and loss of revenue due to a supply chain incident, while for $17 \%$ of respondents, the financial costs were a million or more Euros for a single large incident. Supply chain disruptions not only cause financial loss but can also damage a company's brand or reputation as a result of third-party failures. As reported in the above survey, $17 \%$ of companies suffered damage to their reputation while over $50 \%$ experienced a loss of productivity. The retail sector suffers the most from supply chain disruptions, which are common events, and has an average of ten per year. The second example was reported by Sodhi \& Chopra (2004), and was that of a lightning strike at the Royal Phillips Electronics plant in New Mexico on March 17, 2000 caused a massive surge in the surrounding electrical grid which later turned into a fire and damaged millions of microchips. Nokia Corporation and Ericsson were two major customers of this plant. To obtain a backup supply, Nokia took proactive measures by redesigning its products and began switching its chip orders to other plants immediately after the disaster, while in contrast, Ericsson employed a single sourcing policy. As a result, Ericsson had no other source of microchips which consequently disrupted its production for months and caused $\$ 400$ million lost in sales. In recent years, there have been many disruptions that have affected entire supply chain systems. For example, the 2011 earthquake and tsunami in Japan, which ultimately resulted in major supply chain disruptions across many sectors, caught many companies by surprise. The automotive supply chain, especially for the Japanese companies Toyota and Honda, faced massive loss in their production and sales. In fact, Toyota lost its position as top global car producer in 2011 (Park et al., 2013). In the second half of 2011, a month long flooding in Thailand also had a significant impact on global supply capabilities in a number of high tech sectors. For example, Intel, a renowned disk drive company, lost about $\$ 1$ billion in their sales in the fourth quarter of 2011, because they were unable to source the hard drives that were needed to make new machines. From the above examples, it is clear that supply, production and distribution systems can be unbalanced due to a disruption and that organizations can consequently face both huge financial losses and the loss of customer goodwill. Therefore, it is essential to develop an appropriate disruption management model for minimizing the effect of a disruption in a supply chain network. 
Over the last few decades, supply chains have become one of the most popular and important research topics in operations research and computer science. In the literature, a good number of research works can be found which develop supply chain models under ideal conditions. A few examples of such research includes: a single product, single warehouse and multiple retailers based distribution system (Petrovic et al. 2008), a single manufacturer and single retailer model with demand and manufacturing cost as fuzzy variables (Zhou et al. 2008), a single period and two-stage supply chain coordination problem (Xu and Zhai, 2010) and a three-stage system consisting of supplier, manufacturer and retailer which produces a combination of perfect and imperfect quality items (Sana 2011). Recently, (Sana 2012) developed a model for a three stage supply chain where the system may produce defective items. The production rate, order quantity and number of shipments are decision variables, where the objective is to maximize the expected total profit. Pal, Sana, and Chaudhuri (2012) developed an inventory model for multiple items produced by a manufacturer. It considered multiple suppliers, one manufacturer and multiple retailers with deterministic demand. They maximized the total integrated profit of the supply chain by determining the optimal ordering of lot sizes of the raw materials. In recent years, a few more studies, on developing supply chain models under ideal conditions, can be found in Agnetis et al. (2001), Bottani and Montanari (2010), Kogan and Tapiero (2012), Paul et al. (2014), Masud et al.( 2014), Choi et al. (2013), Petridis (2013), Bai and Liu (2014), and Xu and Meng (2014).

The above researches, along with many others, were carried out under ideal conditions. But in real life situations, a supply chain network can face a sudden disruption in any of its entities. Any disruption may involve production capacity loss, raw material loss, product loss, delayed delivery, customer de-satisfaction, higher product cost, loss of customers and reputation damage in the wider community. So an appropriate disruption management plan can improve a situation. In the literature, a few studies have been found which proposed a disruption management approach. In inventory and supply chain disruption management, the highest numbers of works have been carried out for managing supply disruptions. In the early years, Parlar and Berkin (1991) and Parlar and Perry (1996) developed inventory models that considered supplier availability with deterministic product demand under a continuous review framework. Özekici and Parlar (1999) considered back orders to analyze a production-inventory model under random supply disruptions. Weiss and Rosenthal (1992) developed an optimal inventory policy for EOQ inventory systems which may have a disruption in either supply or demand. They considered that disruption is known a priori and it lasts a random length of time. Some other models of supply disruptions can be found in Mohebbi (2004), Li 
et al. (2004), Tomlin (2006), Mohebbi and Hao (2008), Chopra et al. (2007), Qi et al. (2010) and Schmitt et al. (2010).

Recently, Hou et al. (2010) studied a buy-back contract between a buyer and a backup supplier when the buyer's main supplier experiences disruptions and explored the main supplier's recurrent supply uncertainty through comparative studies and numerical examples. Pal et al. (2012b) considered where two suppliers supplied the raw materials to a manufacturer, where the main supplier may face supply disruption after a random time and the secondary supplier is perfectly reliable but more expensive than the main supplier, to develop a model in a multi-echelon supply chain. Snyder (2014) introduced a simple but effective approximation for a continuous-review inventory model and considered supplier experiences for "wet" and "dry" (operational and disrupted) periods, whose durations are exponentially distributed. Recently, Qi (2013) considered a two supplier concept; (i) supplier 1: primary supplier (cheaper) and (ii) supplier 2: backup supplier (expensive but reliable) to manage supply disruption for a single item continuous-review inventory problem. He considered two strategies to recover from a disruption; (i) If supplier 1 is available when the inventory level at the retailer reaches the reorder point, the retailer orders from supplier 1 and (ii) the retailer will reroute to the backup supplier if supplier 1 does not still recover from a disruption when a waiting cap is reached. Hishamuddin et al. (2014) applied the back order and lost sales concept to manage supply disruption in a two-stage supply chain, which consists of a single supplier and a single retailer. Some other recent works on managing supply disruption can be found in Li et al. (2010), Zhang et al. (2013), Hu et al. (2013), Ray and Jenamani (2014), Yan et al. (2014), and Pal et al. (2014).

The disruption is a very familiar event in the production and supply chain environments. This is a concern because companies face financial, as well as reputation losses, due to disruption. Due to disruption, the entire plan of the organization can be distorted, and thus cause shortage of goods and unfulfilled customer demand. The development of an appropriate recovery policy can help to minimize losses and maintain the goodwill of a company. As of the literature, there exist limited studies that considered disruptions in production and supply chain systems and that also develop approaches to obtain a recovery plan. If a system is disrupted for a given period of time (known as disruption duration), it is necessary to revise the supply chain plan (known as recovery plan) for some periods in the future (known as recovery time window) until the system returns to its normal plan (Hishamuddin et al., 2012). Only a very few studies have been found in the literature, which developed a recovery model after the occurrence of a sudden disruption. Xia et al. (2004) developed a general disruption management approach for a two-stage production and inventory control system 
and they incorporated a penalty cost for deviations of the new plan from the original plan. They introduced a disruption interval which was divided into three parts: pre-disruption, in-disruption and post-disruption, which allowed detailed analysis of disruption effects. They formulated the model as a quadratic mathematical programming problem and introduced the concept of a disruption recovery time window. Eisenstein (2005) introduced the flexible dynamic produce-up-to policy that is able to respond to disruption by adjusting the amount of idle time during recovery and re-established the target idle time as the schedule recovered.

A production disruption recovery model, for a single disruption within a single-stage and single item production system, has been developed by Hishamuddin et al. (2012), for obtaining a recovery plan within a user defined time window, which was an extension of the model of Xia et al. (2004). The study considered back order, as well as the lost sales options. They further extended the concept to develop a transportation disruption recovery plan in a two-stage production and inventory system with a single supplier and a single retailer (Hishamuddin et al., 2013). They also applied the back order and lost sales concepts to develop a supply disruption recovery model in a two-echelon supply chain system with a single supplier and a single retailer (Hishamuddin et al., 2014). Recently, the disruption recovery concept has been applied to manage real-time demand fluctuations in a two-stage supplier retailer coordinated system (Paul et al., 2014a) and to manage real-time production disruptions in a two-stage production-inventory system (Paul et al., 2014c) and in a three-stage mixed production environment (Paul et al. 2015a). Some other disruption recovery models for production-inventory and supply chain system can be found in Tang and Lee (2005), Yang et al. (2005), Shao and Dong (2012), Paul et al. (2013), Paul et al. (2014b), and Paul et al. (2015b).

From the literature review, it is clear that most of the research developed supply chain models under ideal conditions. Although a few of them developed reactive mitigation approaches or disruption recovery models, most of them considered a single supplier and a single retailer, which limits the applicability of such studies. To overcome this limitation, this paper develops a quantitative and simulation approach to recover from a supply disruption after its occurrence, for a three-tier supply chain with multiple suppliers and multiple retailers. Existing studies developed disruption recovery policies for only a single supply disruption. In this paper, we consider a three-tier supply chain system and deal with both single, as well as multiple disruptions one after another as a series, on a real-time basis. We consider disruption events that are not known and cannot be predicted in advance. We first develop a mathematical model for coping with a single supply disruption. Then a new efficient heuristic is proposed for generating a recovery/revised plan after a disruption. In our 
experimental study, we use a random probability distribution to generate disruption parameters, such as disrupted raw material, and disruption durations. Then, we solve the mathematical model to obtain the revised plan after the occurrence of a disruption. We also consider multiple disruptions, one after another in a series, that can occur at any time at any supplier and that may or may not affect the plans revised after previous disruptions. If a new disruption occurs during the recovery time window of another, a new recovery plan which considers the effects of both disruptions must be derived. Accordingly, as this is a continuous process, we extend the mathematical model and the heuristic to deal with a series of disruptions on a real-time basis, by incorporating a modified version of those developed for a single disruption. We have compared the heuristic solutions with those obtained by a standard search algorithm for a good number of randomly generated disruption test problems, and they show the consistent performance of our heuristic. Finally, a simulation model is developed to analyze the effect of randomly generated disruption events that are not known in advance. We have performed many random experiments and their numerical results to explain the usefulness of the developed models and methodologies.

The main contributions of this paper can be summarized as follows.

i. Development of a new reactive mitigation approach for managing raw material supply disruption in a three-tier supply chain system with multiple suppliers, a single manufacturer and multiple retailers. As a disruption scenario is not known in advance and is not possible to predict, the recovery plan is revised for some future periods after the disruption occurs on a real-time basis.

ii. Development of a new efficient heuristic for generating a revised plan after a disruption.

iii. Extension of this heuristic to deal with multiple disruptions, after the occurrence of each disruption, on a real-time basis. As any new disruptions may or may not affect the plans revised after the previous ones, their scenarios may be dependent or independent, both of which the extended heuristic can handle.

iv. The conduct of many random experiments to validate the heuristics and develop a simulation model which closely emulates real-world processes.

The remainder of the paper is organized as follows. The problem description and mitigation strategy are presented in Section 2, and the mathematical modelling in Section 3. The solution approaches, and experimentation and results analysis, are provided in Sections 4 and 5 respectively. Finally, conclusions are drawn and future research directions are suggested in the last section. 


\section{Problem description and mitigation strategy}

We consider a three-tier manufacturing supply chain system with multiple raw material suppliers and retailers. We assume that each supplier supplies one type of raw material. That means the number of suppliers is equal to the number of different types of raw materials required in the production process. The products are produced in batches in a single manufacturing plant. After production, the products are delivered to the retailers according to their demand. In an ideal plan, the optimal supply, production and delivery quantities are $q_{i}, Q$ and $Q_{j}$ respectively, which is shown as a solid line in Figure 1. However the system can face a sudden supply disruption at any time. To manage the system efficiently, it is necessary to generate a recovery plan after the occurrence of a disruption. In Figure 1, after a supply disruption, a recovery plan is generated to revise the supply $\left(X_{k i}\right)$, production $\left(Y_{k}\right)$ and delivery $\left(Z_{k j}\right)$ quantities during the recovery time window, which is shown as a dashed line. The objective is to minimize the total cost during the recovery time window, while being subject to supply, production capacity, demand, and delivery constraints.

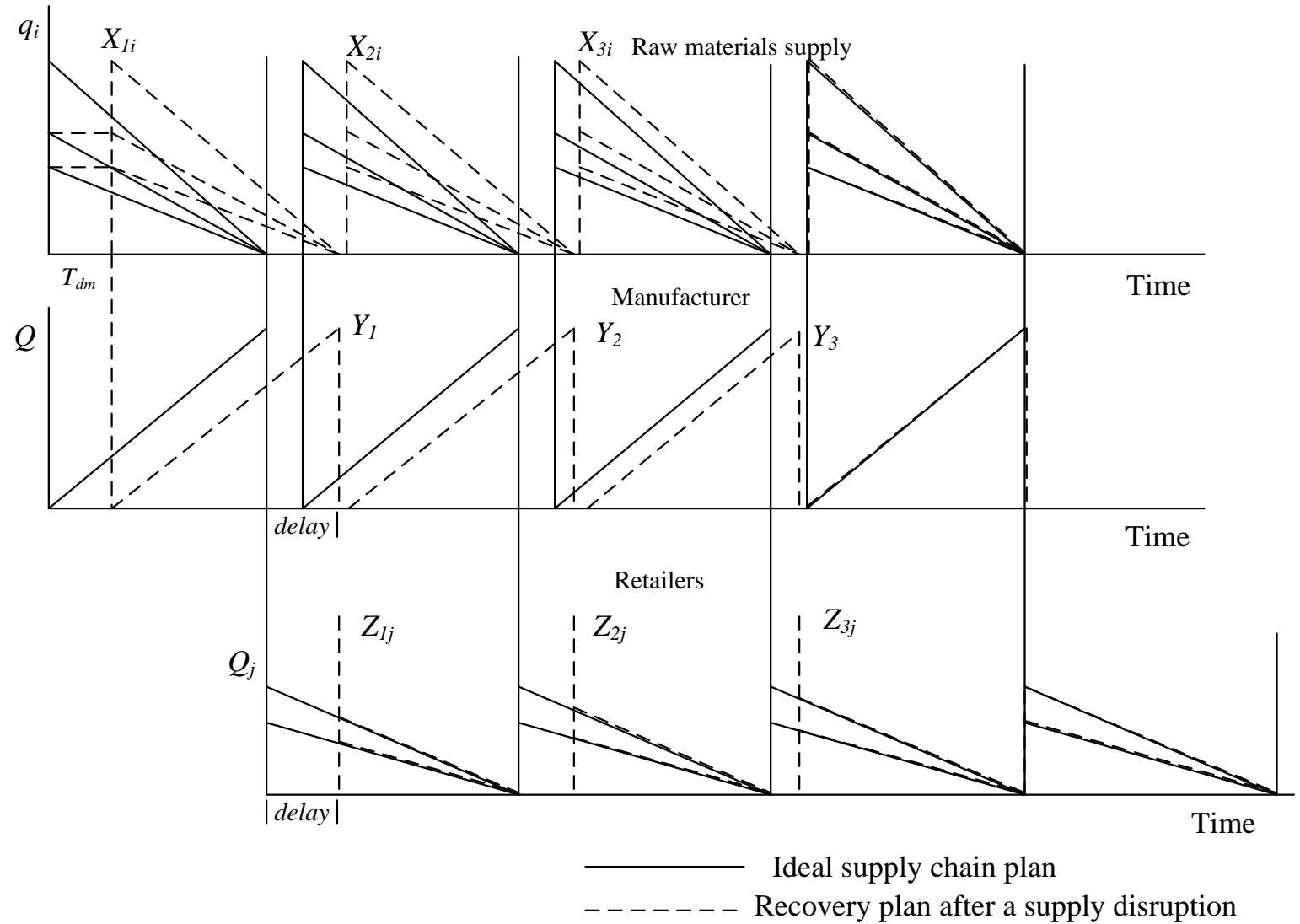

Fig. 1: Recovery plan after the occurrence of a disruption

In real-life situations, the supply chain system can face multiple supply disruptions, one after another, as a series. When a disruption occurs, a recovery plan can be generated by solving the 
mathematical model for a single disruption. If a new disruption occurs after the recovery time window of another disruption, then the later one can be considered as an independent disruption and the recovery plan can be made similar to the previous one. After finalizing the recovery plan, if another disruption occurs within the recovery time window, then the supply, production and delivery plan need to be revised again to consider the effect of both disruptions. This makes the case more complex for recovery planning. In practice, to minimize the effect of disruptions, they must be dealt with on a real-time basis, whether this is a single occurrence of disruption or a series of disruptions. For a series of disruptions, the plan is revised every time, after each occurrence of a disruption, as long as disruptions take place in the system.

\subsection{Reactive mitigation strategy}

A supply disruption can be defined as any form of interruption in the raw material supply. It may be caused due to delay, unavailability, or any other form of disturbance. The recovery/revised plan is a new schedule that includes the revised supply, production and delivery quantities in each cycle, for future periods, while ensuring the minimization of the total cost in the recovery time window. The number of future cycles allocated to return to the original schedule from the disrupted cycle, defines the recovery time window, and is decided by the management of the organization. As we assume that the production rate is higher than the demand rate, there is an idle timeslot between any two consecutive production cycles. If the raw material supply is interrupted for a time period, known as disruption duration, the utilization of the idle timeslots, in future production cycles, may help to recover from the disruption. However, it may also involve costly back order and/or lost sales due to a long disruption duration and delayed production and delivery. In this paper, to recover from a disruption, the following two options are considered.

i. Back orders: the portion of demand that cannot be fulfilled at the scheduled time, but that will be delivered at a later date, with a penalty, if the system is capable.

ii. Lost sales: the portion of demand lost if customers will not wait for the required stock to be replenished as a consequence of the system not being capable of fulfilling demand.

\subsection{Real-time disruption recovery}

A disruption recovery plan is basically a rescheduling of supply, production and delivery plans for some future periods, after the occurrence of a disruption, in order to return to its normal plan. We consider a disruption event that is not known and cannot be predicted in advance. In this paper, we consider random disruption scenarios which can be defined as combinations of disrupted raw material, and disruption durations. In any supply chain environment, the system can face multiple 
disruptions, one after another, on a real-time basis. In this case, one disruption can occur within the recovery window of another, which is known as a dependent disruption, and as this is a complex situation, the combined effect of dependent disruptions should be considered in the development of a recovery plan. This is achieved by re-optimizing the supply, production and delivery plans within the new recovery window under the changed supply, production and delivery environment. The proposed mathematical model and heuristic (discussed earlier) for dealing with a single disruption are later extended to consider multiple disruptions on a real-time basis, and are capable of handling dependent, independent and mixtures of dependent and independent disruptions on a real-time basis.

\subsection{Notations used for a single disruption case}

In this study, we have used the following notations for a single disruption case.

$D_{j} \quad$ Annual demand of the final product of retailer $j$

$D \quad$ Annual total demand of the final product $=\sum_{j=1}^{J} D_{j}$

$d_{i} \quad$ Annual demand of raw material $i$

$B_{1} \quad$ Back order cost for the manufacturer (\$ per unit per unit time)

$B_{2} \quad$ Back order cost for retailer (\$ per unit per unit time)

$B_{q k j} \quad$ Back order quantity of retailer $j$ during the $k^{\text {th }}$ cycle

$L_{1} \quad$ Lost sales cost for the manufacturer (\$ per unit)

$L_{2} \quad$ Lost sales cost for a retailer (\$ per unit)

$H_{1 i} \quad$ Holding cost of raw material $i$ (\$ per unit per year)

$\mathrm{H}_{2} \quad$ Holding cost of the final product at the manufacturer (\$ per unit per year)

$H_{3 j} \quad$ Holding cost of retailer $j$ (\$ per unit per year)

$N_{i} \quad$ Units of raw material $i$ required to produce one unit of the final product

$K \quad$ Number of cycles in the revised plan - known from management

$P \quad$ Annual production rate $(P>D)$

Q Production lot size

$q_{i} \quad$ Supply lot size of raw material $i$

$Q_{j} \quad$ Delivery lot size of the final product for retailer $j$

$S_{1 i} \quad$ Ordering cost of raw material $i$ (\$ per order)

$S_{2} \quad$ Set-up cost of the manufacturer (\$ per order)

$S_{3 j} \quad$ Ordering cost of retailer $j$ (\$ per order)

$s_{t} \quad$ Set-up time after the production of a lot 
$T_{i d l e}$ Idle time after the production of a lot $=\frac{Q}{D}-\frac{Q}{P}-s_{t}$

$T_{d m} \quad$ Supply disruption duration of the $m^{\text {th }}$ raw material

$X_{k i} \quad$ Supply lot size of raw material $i$ in the revised plan

$Y_{k} \quad$ Production lot size in the revised plan

$Z_{k j} \quad$ Delivery lot size of the final product to retailer $j$ in the revised plan

\subsection{Assumptions of the study}

We have made the following assumption in this study.

i. The production rate is greater than the demand rate.

ii. A single item is produced in the system.

iii. The recovery plan starts just after the occurrence of a disruption.

iv. The recovery plan considers both lost sales and back order options.

v. No inventory buffers are present in the system.

\section{Mathematical modelling}

In this section, we develop a mathematical model for managing a single occurrence of a disruption caused by a supply disruption, by firstly presenting a mathematical model for an ideal supply chain plan. Then, we formulate a revised plan as a constrained optimization problem that minimizes total cost, which is derived from the relevant costs, subject to production capacity, supply, delivery, and product demand constraints. The decision variables are the revised quantities of production, delivery, supply, back orders and lost sales during the recovery time window. Some propositions are also developed to analyze the properties of some important parameters.

\subsection{Mathematical model for the ideal plan}

The economic supply, production and delivery sizes under ideal conditions are derived in this section. The optimal ideal plan is obtained by minimizing the total annual holding, ordering and setup cost.

Annual raw material holding cost $=\frac{Q D}{2 P} \sum_{i=1}^{I} N_{i} H_{1 i}$

Annual raw material ordering cost $=\frac{D}{Q} \sum_{i=1}^{I} S_{1 i}$

Manufacturer annual holding cost $=\frac{Q}{2} H_{2} \frac{D}{P}$

Manufacturer annual set-up cost $=\frac{D}{Q} S_{2}$

Retailer annual holding cost $=\frac{Q}{2 D} \sum_{j=1}^{J} D_{j} H_{3 j}$

Retailer annual ordering cost $=\frac{D}{Q} \sum_{j=1}^{J} S_{3 j}$ 
Total cost,

$T C=\frac{Q D}{2 P} \sum_{i=1}^{I} N_{i} H_{1 i}+\frac{D}{Q} \sum_{i=1}^{I} S_{1 i}+\frac{Q}{2} H_{2} \frac{D}{P}+\frac{D}{Q} S_{2}+\frac{Q}{2 D} \sum_{j=1}^{J} D_{j} H_{3 j}+\frac{D}{Q} \sum_{j=1}^{J} S_{3 j}$

Now, to minimize the total cost, $\frac{d}{d Q}(T C)=0$

After simplifying, the optimal ideal plan is obtained from (8) - (10).

$Q=\sqrt{\frac{2 D\left(\sum_{i=1}^{I} S_{1 i}+S_{2}+\sum_{j=1}^{J} S_{3 j}\right)}{\frac{D}{P} \sum_{i=1}^{I} N_{i} H_{1 i}+\frac{H_{2} D}{P}+\frac{1}{D} \sum_{j=1}^{J} D_{j} H_{3 j}}}$

$q_{i}=N_{i} Q$

$Q_{j}=\frac{Q D_{j}}{D}$

\subsection{Mathematical model for recovery plan after a single disruption}

In this section, we develop a mathematical model for managing a supply disruption. To formulate the mathematical model for determining the revised plan after a supply disruption, we consider the costs of holding, ordering, set-up, back orders and lost sales. Finally, we develop a mathematical model in which the total cost is to be minimized subject to capacity, delivery, supply, and product demand constraints.

\subsubsection{Different costs}

Raw material holding cost

$=\sum_{i=1}^{I} \frac{X_{1 i}}{2} H_{1 i} \frac{Y_{1}}{P}+\sum_{\forall i \neq n} X_{1 i} T_{d m} H_{1 i}+\sum_{k=1}^{K} \sum_{i=2}^{I} \frac{X_{k i}}{2} H_{1 i} \frac{Y_{k}}{P}$

Raw material ordering cost $=K \sum_{i=1}^{I} S_{1 i}$

Manufacturer holding cost $=\sum_{k=1}^{K} \frac{Y_{k}^{2}}{2 P} H_{2}$

Manufacturer set-up cost $=K S_{2}$

Manufacturer back order cost

$=B_{1} \sum_{k=1}^{K} Y_{k} \cdot$ delay $_{k}$

Where, delay $_{k}=T_{d m}+\sum_{i=1}^{k} \frac{Y_{i}}{P}+(k-1) s_{t}-\frac{(k-1) Q}{D}-\frac{Q}{P}$

Manufacturer lost sales cost $=L_{1}\left(K Q-\sum_{k=1}^{K} Y_{k}\right)$

Retailer holding cost $=\sum_{k=1}^{K} \sum_{j=1}^{J} \frac{\left(Z_{k j}-B_{q k j}\right)^{2}}{2 D_{j}} H_{3 j}$

Retailer ordering cost $=K \sum_{j=1}^{J} S_{3 j}$

Retailer back order cost $=B_{2} \sum_{k=1}^{K} \sum_{j=1}^{J} \frac{\text { delay }_{k}}{2} B_{q k j}$

Retailer lost sales $=L_{2}\left(K \sum_{j=1}^{J} Q_{j}-\sum_{k=1}^{K} \sum_{j=1}^{J} Z_{k j}\right)$ 


\subsubsection{Final mathematical model for a single disruption}

The total cost function, which is the objective function, is obtained by adding all the costs presented in $(11)-(20)$. Subject to the following constraints presented in $(21)-(28)$.

$Y_{k} \leq Q ; \forall k$ [To meet the delivery requirements]

$X_{k i} \leq q_{i} ; \forall i, k$ [Raw material supply constraint]

$Z_{k j} \leq Q_{j} ; \forall j, k$ [Final product delivery constraint]

delay $_{k} \geq 0 ; \forall k$ [Non-negative delay time]

$\frac{Q}{D}-\frac{Q}{P}-s_{t} \geq 0$ [Non-negative idle time]

$K Q-\sum_{k=1}^{K} Y_{k} \geq 0$ [Lost sales quantity constraint]

$\sum_{k=1}^{K} Y_{k} \leq P\left(K * \frac{Q}{D}-(K-1) * s_{t}-T_{d m}\right)$ [Production capacity constraints]

$X_{k i}, Y_{k}, Z_{k j} \geq 0 ; \forall i, j, k$ [Non-negative constraint]

Proposition 1: For a given $H_{1 i}, H_{2}, H_{3 j}, S_{1 i}, S_{2}, S_{3 j}, D_{j}, P, B_{1}, B_{2}, L_{1}$ and $L_{2}$, the revised plan will only use the back order option if $T_{d m} \leq K T_{i d l e}$.

Proof: Idle time per cycle, $T_{i d l e}=\frac{Q}{D}-\frac{Q}{P}-s_{t}$. As there are $K$ cycles in the recovery plan, so the total idle time during the revised plan is $K T_{i d l e}$. The quantity to be produced during the idle time is $P K T_{\text {idle }}$.

Now, quantity loss during the duration of the disruption is $T_{d m} P$. The system will thus be able to recover by using only back order options, if the quantity to be produced during the idle time is greater than the quantity loss during the disruption duration.

So, $P K T_{\text {idle }} \geq T_{d m} P$, hence $T_{d m} \leq K T_{\text {idle }}$.

Proposition 2: For a given $H_{1 i}, H_{2}, H_{3 j}, S_{1 i}, S_{2}, S_{3 j}, D_{j}, P, B_{1}, B_{2}, L_{1}$ and $L_{2}$, both back order and lost sales will exist in the revised plan if $T_{d m}>K T_{i d l e}$.

Proof: This is the opposite consequence of Proposition 1.

Proposition 3: For a given $H_{1 i}, H_{2}, H_{3 j}, S_{1 i}, S_{2}, S_{3 j}, D_{j}, P, B_{1}, B_{2}, L_{1}$ and $L_{2}$, the revised plan will only use the lost sales option if $\left(B_{1}+B_{2}\right)\left(\frac{Q}{D}-\frac{Q}{P}-s_{t}\right)>\left(L_{1}+L_{2}\right)$.

Proof: Idle time per cycle $=\frac{Q}{D}-\frac{Q}{P}-s_{t}$ and total back order cost per unit per unit time $=B_{1}+B_{2}$. So, back order cost per unit $=\left(B_{1}+B_{2}\right)\left(\frac{Q}{D}-\frac{Q}{P}-s_{t}\right)$ 
Now, lost sales cost per unit $=\left(L_{1}+L_{2}\right)$. Hence if $\left(B_{1}+B_{2}\right)\left(\frac{Q}{D}-\frac{Q}{P}-s_{t}\right)>\left(L_{1}+L_{2}\right)$, then the back order cost will be higher than the lost sales cost, so it is favorable that the revised plan will only use the lost sales option.

Proposition 4: For a given $H_{1 i}, H_{2}, H_{3 j}, S_{1 i}, S_{2}, S_{3 j}, D_{j}, P, B_{1}, B_{2}, L_{1}$ and $L_{2}$, the back order quantity of retailer to its customers is $B_{q k j}=Z_{k j}-D_{j}\left(\frac{Q}{D}-\right.$ delay $\left._{k}\right)$ if $Z_{k j} \geq D_{j}\left(\frac{Q}{D}-\right.$ delay $\left._{k}\right)$, and is $B_{q k j}=0$ if $Z_{k j}<D_{j}\left(\frac{Q}{D}-\right.$ delay $\left._{k}\right)$.

Proof: After a disruption, the delay time for delivering the final product of the $k^{\text {th }}$ cycle to a retailer is $\operatorname{delay}_{k}$. So, the remaining period of the demand cycle is $\left(\frac{Q}{D}-\right.$ delay $\left._{k}\right)$. The demand during the remaining period for retailer $j$ is $D_{j}\left(\frac{Q}{D}-\right.$ delay $\left._{k}\right)$. Now the quantity received by retailer $j$ in the $k^{t h}$ cycle is $Z_{k j}$. If $Z_{k j} \geq D_{j}\left(\frac{Q}{D}-\right.$ delay $\left._{k}\right)$, then the excess quantity than $D_{j}\left(\frac{Q}{D}-\right.$ delay $\left._{k}\right)$ should be back ordered. So, the retailer back order quantity, $B_{q k j}=Z_{k j}-D_{j}\left(\frac{Q}{D}-\right.$ delay $\left._{k}\right)$ and if $Z_{k j}<$ $D_{j}\left(\frac{Q}{D}-\right.$ delay $\left._{k}\right)$, then the retailer back order quantity, $B_{q k j}=0$, because back orders are no longer needed in this condition.

\subsection{Dynamic mathematical model for recovery plans of multiple disruptions}

Based on the formulation of the mathematical model for a single disruption, we have also developed a dynamic mathematical model for a series of disruptions. Here we have presented the mathematical model after the $n^{\text {th }}$ disruption. We have used the following additional notations for the mathematical formulation.

$l \quad$ Number of cycles to the current disruption from the previous disruption

$X_{k i, n} \quad$ Supply lot size in the revised plan after the $n^{\text {th }}$ disruption

$Y_{k, n} \quad$ Production lot size in the revised plan after the $n^{\text {th }}$ disruption

$Z_{k j, n}$ Delivery lot size in the revised plan after the $n^{\text {th }}$ disruption

$T_{d m, n}$ Actual disruption duration for the $n^{\text {th }}$ disruption

We use $T_{d m, n}^{*}$ as the disruption duration to determine the new revised plan, which considers the effect of both the previous and the current disruption. We calculate $T_{d m, n}^{*}$ by using the equations (29) and (30).

For the first disruption: $T_{d m, 1}^{*}=T_{d m, 1}$ 
From the second disruption:

$T_{d m, n}^{*}=\left\{\begin{array}{c}T_{d m, n}+T_{d m, n-1}^{*}-l\left(\frac{Q}{D}-\frac{Q}{P}-s_{t}\right) ; \text { if } T_{d m, n-1}^{*}>l\left(\frac{Q}{D}-\frac{Q}{P}-s_{t}\right) \\ T_{d m, n} ; \text { if } T_{d m, n-1}^{*} \leq l\left(\frac{Q}{D}-\frac{Q}{P}-s_{t}\right) \text { or } l>K\end{array}\right.$

\subsubsection{Different costs in the recovery plan after the $n^{\text {th }}$ disruption}

Raw material holding cost

$=\sum_{i=1}^{I} \frac{X_{1 i, n}}{2} H_{1 i} \frac{Y_{1, n}}{P}+\sum_{\forall i \neq n} X_{1 i, n} T_{d m, n} H_{1 i}+\sum_{k=1}^{K} \sum_{i=2}^{I} \frac{X_{k i, n}}{2} H_{1 i} \frac{Y_{k, n}}{P}$

Raw material ordering cost $=K \sum_{i=1}^{I} S_{1 i}$

Manufacturer holding cost $=\sum_{k=1}^{K} \frac{Y_{k, n}^{2}}{2 P} H_{2}$

Manufacturer ordering cost $=K S_{2}$

Manufacturer back order cost $=B_{1} \sum_{k=1}^{K} Y_{k, n} *$ delay $_{k, n}$

Where, delay $_{k, n}=T_{d m, n}+\sum_{i=1}^{k} \frac{Y_{i, n}}{P}+(k-1) s_{t}-\frac{(k-1) Q}{D}-\frac{Q}{P}$

Manufacturer lost sales cost $=L_{1}\left(K Q-\sum_{k=1}^{K} Y_{k, n}\right)$

Retailer holding cost $=\sum_{k=1}^{K} \sum_{j=1}^{J} \frac{\left(Z_{k j, n}-B_{q k j, n}\right)^{2}}{2 D_{j}} H_{3 j}$

Retailer ordering cost $=K \sum_{j=1}^{J} S_{3 j}$

Retailer back order cost $=B_{2} \sum_{k=1}^{K} \sum_{j=1}^{J} \frac{\text { delay }_{k, n}}{2} B_{q k j, n}$

Retailer lost sales $=L_{2}\left(K \sum_{j=1}^{J} Q_{j}-\sum_{k=1}^{K} \sum_{j=1}^{J} Z_{k j, n}\right)$

\subsubsection{Final mathematical model for a series of disruptions}

The total cost function after the $n^{\text {th }}$ disruption, which is the objective function, is obtained by adding all the costs in (31) - (40). Subject to the following constraints presented in (41) - (47).

$Y_{k, n} \leq Q ; \forall k$ [To meet the delivery requirements]

$X_{k i, n} \leq q_{i} ; \forall i, k$ [Raw material supply constraint]

$Z_{k j, n} \leq Q_{j} ; \forall j, k$ [Final product delivery constraint]

delay $_{k, n} \geq 0 ; \forall k$ [Non-negative delay time]

$K Q-\sum_{k=1}^{K} Y_{k, n} \geq 0$ [Lost sales quantity constraint]

$\sum_{k=1}^{K} Y_{k, n} \leq P\left(K * \frac{Q}{D}-(K-1) * s_{t}-T_{d m, n}\right)$ [Production capacity constraints]

$X_{k i, n}, Y_{k, n}, Z_{k j, n} \geq 0 ; \forall i, j, k$ [Non-negative constraint] 


\section{Solution approaches}

In this section, a heuristic is developed to obtain the recovery plan by solving the developed model for a single disruption. To judge the quality of the heuristic solutions, the model is also solved by applying a pattern search (PS) technique, which is a standard search algorithm for solving constrained optimization problems. We also develop a simulation model to make the disruption problem closer to a real-world process. Finally, we extend the heuristic for managing multiple disruptions, one after another as a series, on a real-time basis. Both the heuristics and the PS technique were coded in MATLAB R2012a, and were executed on an Intel core i7 processor with 8.00 GB RAM and a $3.40 \mathrm{GHz}$ CPU.

\subsection{Proposed heuristic for recovery plan after a single disruption}

In this section, a heuristic is developed to obtain the recovery plan after a single occurrence of disruption. The steps of the heuristic are as follows.

Step 1: Input all information about the ideal system.

Step 2: Determine $Q, q_{i}$ and $Q_{j}$ for the optimal ideal plan by using (8) - (10) and also determine production time, cycle time and idle time.

Step 3: Input disruption information, such as: disrupted raw material, disruption duration and recovery period.

Step 4: If $\left(B_{1}+B_{2}\right)\left(\frac{Q}{D}-\frac{Q}{P}-s_{t}\right) \leq\left(L_{1}+L_{2}\right)$ and $T_{d m} \leq K * T_{\text {idle }}$, then

$$
\begin{aligned}
& Y_{k}=Q ; \forall k \\
& X_{k i}=N_{i} * Y_{k} ; \forall i, k \\
& Z_{k j}=\frac{Y_{k} * D_{j}}{D} ; \forall j, k
\end{aligned}
$$

If $T_{d m} \leq T_{\text {idle }}$, then

$$
\begin{aligned}
& \text { delay }_{1}=T_{d m}+\frac{Y_{1}}{P}-\frac{Q}{P} \\
& \text { delay }_{k}=0 ; \text { For } k=2,3, \ldots, K
\end{aligned}
$$

If $T_{\text {idle }}<T_{d m} \leq 2 T_{\text {idle }}$, then

$$
\text { delay }_{1}=T_{d m}+\frac{Y_{1}}{P}-\frac{Q}{P}
$$$$
\text { delay }_{2}=T_{d m}+\frac{Y_{1}+Y_{2}}{P}+s_{t}-\frac{Q}{D}-\frac{Q}{P}
$$$$
\text { delay }_{k}=0 \text {; for } k=3,4, \ldots, K
$$

If $(\ddot{K-1}-1) T_{i d l e}<T_{d m} \leq K T_{i d l e}$, then

$$
\text { delay }_{k}=T_{d m}+\sum_{i=1}^{k} \frac{Y_{i}}{P}+(k-1) s_{t}-\frac{(k-1) Q}{D}-\frac{Q}{P} ; \forall k
$$

Step 5: If $\left(B_{1}+B_{2}\right)\left(\frac{Q}{D}-\frac{Q}{P}-s_{t}\right) \leq\left(L_{1}+L_{2}\right)$ and $T_{d m}>K T_{i d l e}$, then

$$
\begin{aligned}
& Y_{1}=Q \\
& Y_{2}=Q-P\left[T_{d m}-K *\left(\frac{Q}{D}-\frac{Q}{P}-s_{t}\right)\right]
\end{aligned}
$$$$
Y_{k}=Q ; \text { For } k=3,4, \ldots, K
$$

$X_{k i}=N_{i} * Y_{k} ; \forall i, k$ 


$$
\begin{aligned}
& Z_{k j}=\frac{Y_{k} * D_{j}}{D} ; \forall j, k \\
& \text { delay }_{k}=T_{d m}+\sum_{i=1}^{k} \frac{Y_{i}}{P}+(k-1) s_{t}-\frac{(k-1) Q}{D}-\frac{Q}{P} ; \forall k
\end{aligned}
$$

Step 6: If $\left(B_{1}+B_{2}\right)\left(\frac{Q}{D}-\frac{Q}{P}-s_{t}\right)>\left(L_{1}+L_{2}\right)$ then

$$
\begin{aligned}
& Y_{1}=Q-T_{d m} * P \\
& Y_{k}=Q ; \text { For } k=2,3, \ldots ., K \\
& X_{k i}=N_{i} * Y_{k} ; \forall i, k \\
& Z_{k j}=\frac{Y_{k} * D_{j}}{D} ; \forall j, k \\
& \text { delay }_{k}=0 ; \forall k
\end{aligned}
$$

Step 7: Determine the lost sales and back order quantities.

Step 8: Determine the different costs and record the results.

Step 9: Stop.

\subsection{Simulation model}

We develop a simulation model to make the disruption model closer to a real-world problem by using the following steps.

Step A: Generate a random number for choosing a disrupted raw material by using a uniform distribution.

Step B: Generate a random number for the disruption duration by using an exponential distribution.

Step C: Solve the disruption management problem by using the heuristic for a single disruption.

Step D: Repeat steps A to C 2000 times.

Step E: Record the results.

Step F: Stop.

\subsection{Extended heuristic for recovery plans of multiple disruptions}

We extend the heuristic, developed for a single disruption, for managing multiple disruptions, after the occurrence of each disruption as a series, on a real-time basis. To do this, a recovery plan is obtained from the heuristic after each disruption, with the revised production, supply and delivery plans saved and then used as a foundation for recovering from the next disruption. The steps in the extended heuristic for managing multiple disruptions are described below.

Step 1: Input the disrupted raw material and $T_{d m, 1}$ for the first disruption.

Step 2: Update the parameter $T_{d m}=T_{d m, 1}^{*}$ and also update the decision variables as $X_{k i}=X_{k i, 1}$ and $Y_{k}=Y_{k, 1}$ and $X_{k j}=X_{k j, 1}$

Step 3: Solve the model by using the heuristic for the single disruption under the updated parameters.

Step 4: Record the revised plan and calculate the different costs.

Step 5: If there is any other disruption, 
5.1 Later when known, input the disrupted raw material, disrupted cycle number from the previous disruption $(l)$, and disruption duration $\left(T_{d m, n}\right)$ for the next disruption.

5.2 Calculate $T_{d m, n}^{*}$ by using equation (30).

5.3 Update the disruption duration as $T_{d m}=T_{d m, n}^{*}$ and also update the decision variables as $X_{k i}=X_{k i, n}, Y_{k}=Y_{k, n}$ and $X_{k j}=X_{k j, n}$.

\subsection{Go to step 3 .}

Step 6: Record the results.

Step 7: Stop.

\section{Experimentations and results analysis}

In this section, we have analyzed the results for both the ideal and revised plans by performing random experimentations. We have also analyzed the results for both a single and multiple disruptions.

\subsection{Ideal plan}

We consider the following data for the ideal supply chain plan with three raw material suppliers and four retailers.

$I=3 ; J=4 ; D_{j}=[15,000,25,000,20,000,30,000] ; P=100,000 ; N_{i}=[1,3,2] ; H_{1 i}=[2,2.5,2.2]$;

$S_{1 i}=[100,80,120] ; H_{2}=3 ; S_{2}=150 ; H_{3 j}=[1.2,1.5,1.7,1.4] ; S_{3 j}=[50,60,60,50] ;$

$$
s_{t}=0.000228
$$

We have used equations (8) - (10) to determine the ideal plan which is obtained as follows.

$Q=2,689.6$;

$q_{i}=[2689.6,8068.8,5379.2] ;$ and

$Q_{j}=[448.3,747.1,597.7,896.5]$

\subsection{Recovery plan after a single disruption}

In this section, the solutions after a single disruption are analyzed. Although we experimented on many random disruption test problems, for illustrative purposes, six different sample instances were used by arbitrarily changing the disruption data, with their parameters shown in Table 1 . We consider the same data of the ideal plan with the following additional data to obtain the revised plan.

$$
B_{1}=20, B_{2}=10, L_{1}=25, L_{2}=15 \text { and } K=5
$$


Table 1: Disruption instances for a single disruption

\begin{tabular}{|c|c|c|}
\hline Instance number & Disrupted raw material & Disruption duration \\
\hline 1 & 1 & 0.005 \\
\hline 2 & 1 & 0.020 \\
\hline 3 & 2 & 0.010 \\
\hline 4 & 2 & 0.025 \\
\hline 5 & 3 & 0.008 \\
\hline 6 & 3 & 0.022 \\
\hline
\end{tabular}

The results for the disruption instances are presented in Table 2, which includes back orders, lost sales and total cost. For a sample representation, the recovery plans for disruption instances 1 and 2 are presented in Appendix B.

Table 2: Results in recovery plan for disruption instances

\begin{tabular}{|c|c|c|c|}
\hline Instance number & $\begin{array}{c}\text { Total Back Order } \\
\text { Cost }\end{array}$ & $\begin{array}{c}\text { Total Lost Sales } \\
\text { Cost }\end{array}$ & Total Cost \\
\hline 1 & 402.94 & 0 & $7,236.50$ \\
\hline 2 & $2,672.56$ & $24,790.60$ & $34,408.30$ \\
\hline 3 & $1,339.69$ & 0 & $8,131.25$ \\
\hline 4 & $2,904.75$ & $44,790.60$ & $54,272.06$ \\
\hline 5 & 889.46 & 0 & $7,738.52$ \\
\hline 6 & $2,762.74$ & $32,790.60$ & $42,351.55$ \\
\hline
\end{tabular}

\subsection{Comparison of results and validation of heuristic}

To judge the quality of the solutions obtained from our proposed heuristic, the solutions of 150 test problems were compared with the results obtained from a standard solution technique, named pattern search (PS) technique. The parameters used in the PS technique are presented in Appendix A. We have generated the random test problems by using a uniform distribution and by varying the data of the disruption parameters. The test problems were solved using both approaches and the heuristic results were compared with the best results (out of 30 independent runs) obtained from the PS technique. The comparison showed that our proposed heuristic is capable of producing high quality solutions. In terms of the quality of the solutions from 150 test problems, the average percentage of deviation of results between the two approaches is only $0.000283 \%$, which can be considered as 
negligible. Indeed, it may merely have been due to rounding errors in the values of the decision variables. The percentage of deviation was calculated by using the equation (48).

$$
\text { Average percentage of deviation }=\frac{1}{M} \sum\left[\frac{\mid \text { Total profit from heuristc-Total profit from PS } \mid}{\text { Total profit from PS }} \times 100 \%\right]
$$

Here, $M$ is the number of test problems.

\subsection{Random experimentation}

We generated many disruption test problems randomly for each raw material supply, and solved them using the heuristic. We analyzed the total cost pattern for random occurrences of disruption over 500 random scenarios, and variations in the different costs according to the disruption duration.

We generated 500 random scenarios for the duration of a supply disruption using an exponential distribution within the range of $[0.0001,1]$, and the total cost pattern, for disruption of raw material 1, is presented in Figure 2. We determined that the mean and standard deviation values of the total cost were 13.2000 and 11.8620 thousand respectively, and the maximum and minimum values were 54.6130 and 6.7060 thousand respectively.

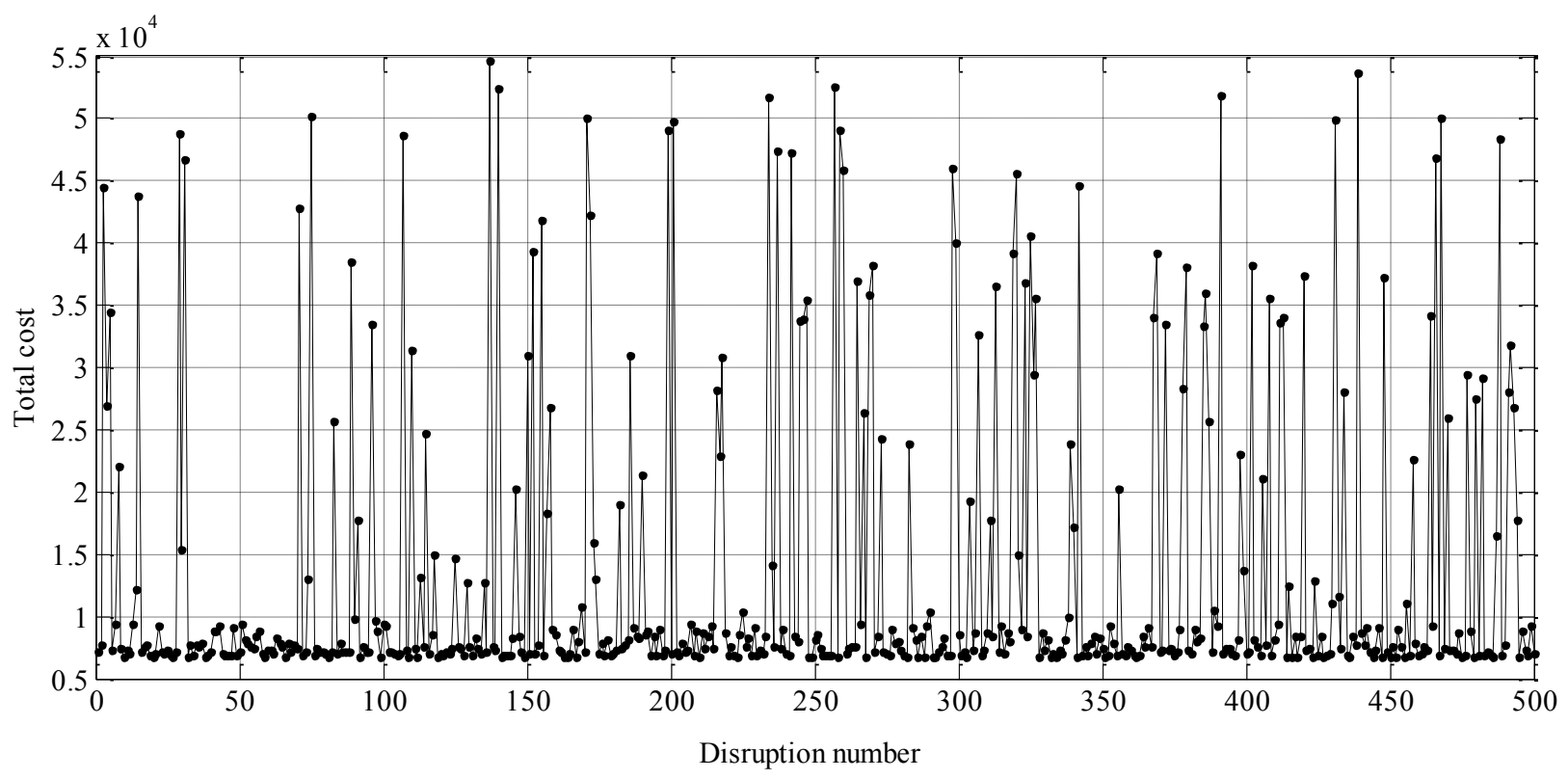

Fig. 2: Total cost vs. disruption number for disruption at raw material 1 


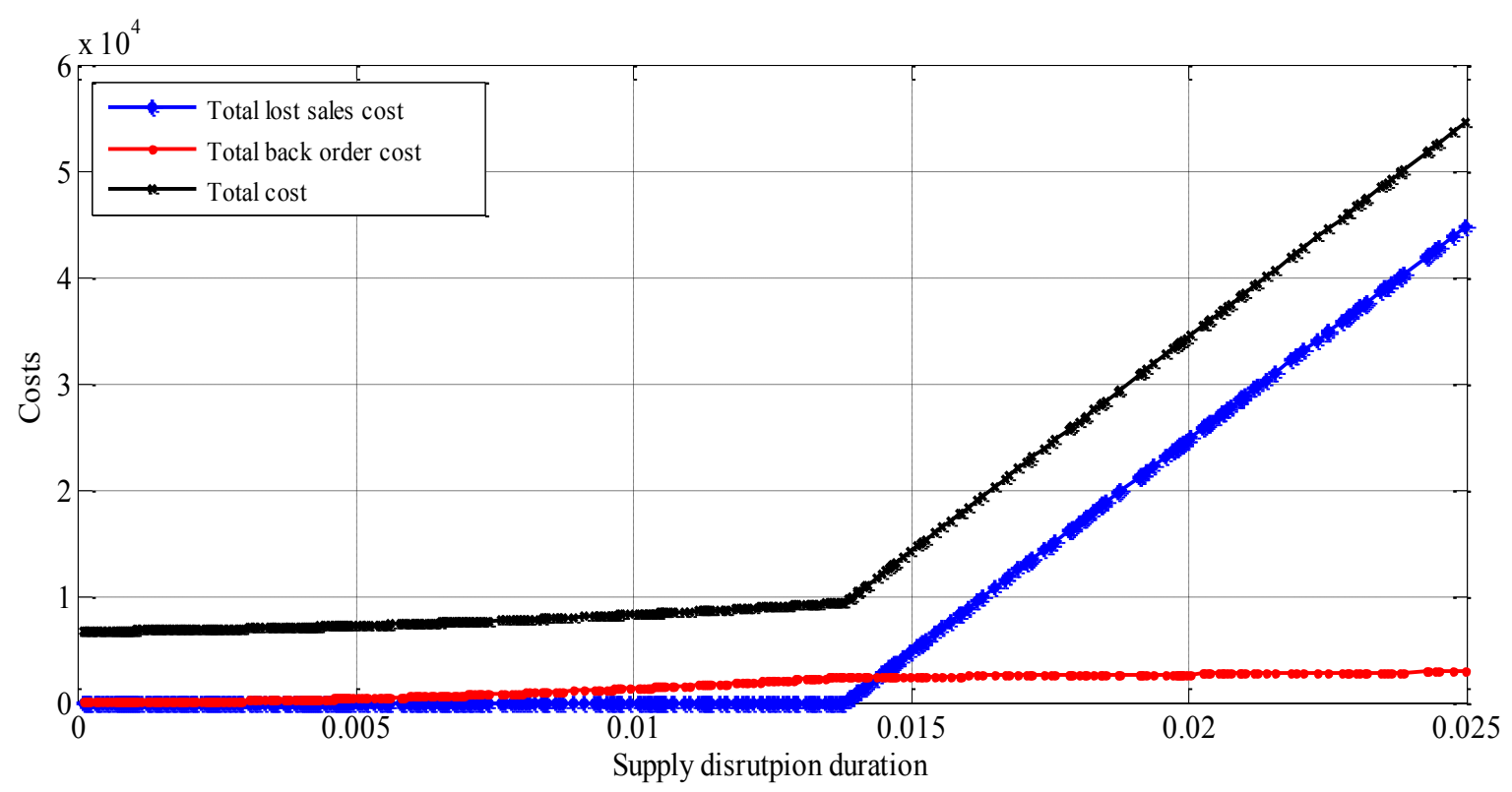

Fig. 3 Different costs vs. disruption duration for disruption of raw material 1

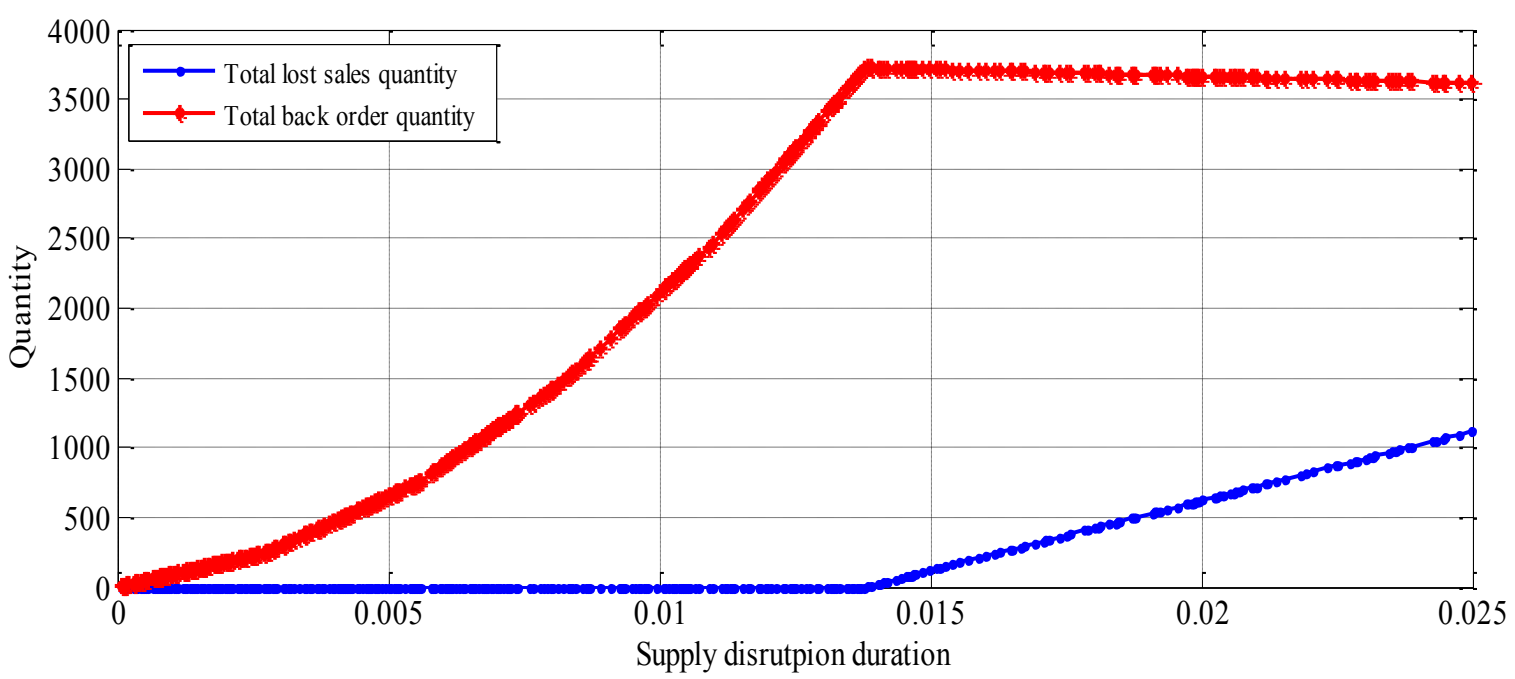

Fig. 4: Lost sales and back order quantity vs. disruption duration for disruption of raw material 1

The variations in the different costs in relation to the duration of a supply disruption, for disruption of raw material 1, are presented in Figure 3. The total cost increases slowly when the duration is less than 0.014 because only back orders are present in the the revised plan. Then, the total cost increases at a higher rate with disruption durations because of the lost sales cost being included in the plan and both back orders and lost sales are present in the revised plan. Figure 4 presents the variations of back orders and lost sales quantities in relation to the disruption duration for disruption of raw material 1 . The back orders quantity increases with the disruption duatrion when the duration is less 
than 0.014 and no lost sales are then present. After then, the lost sales quantity enters in the revised plan and both back orders and lost sales quantities are present. Similar properties have also been found for disruption of raw materials 2 and 3.

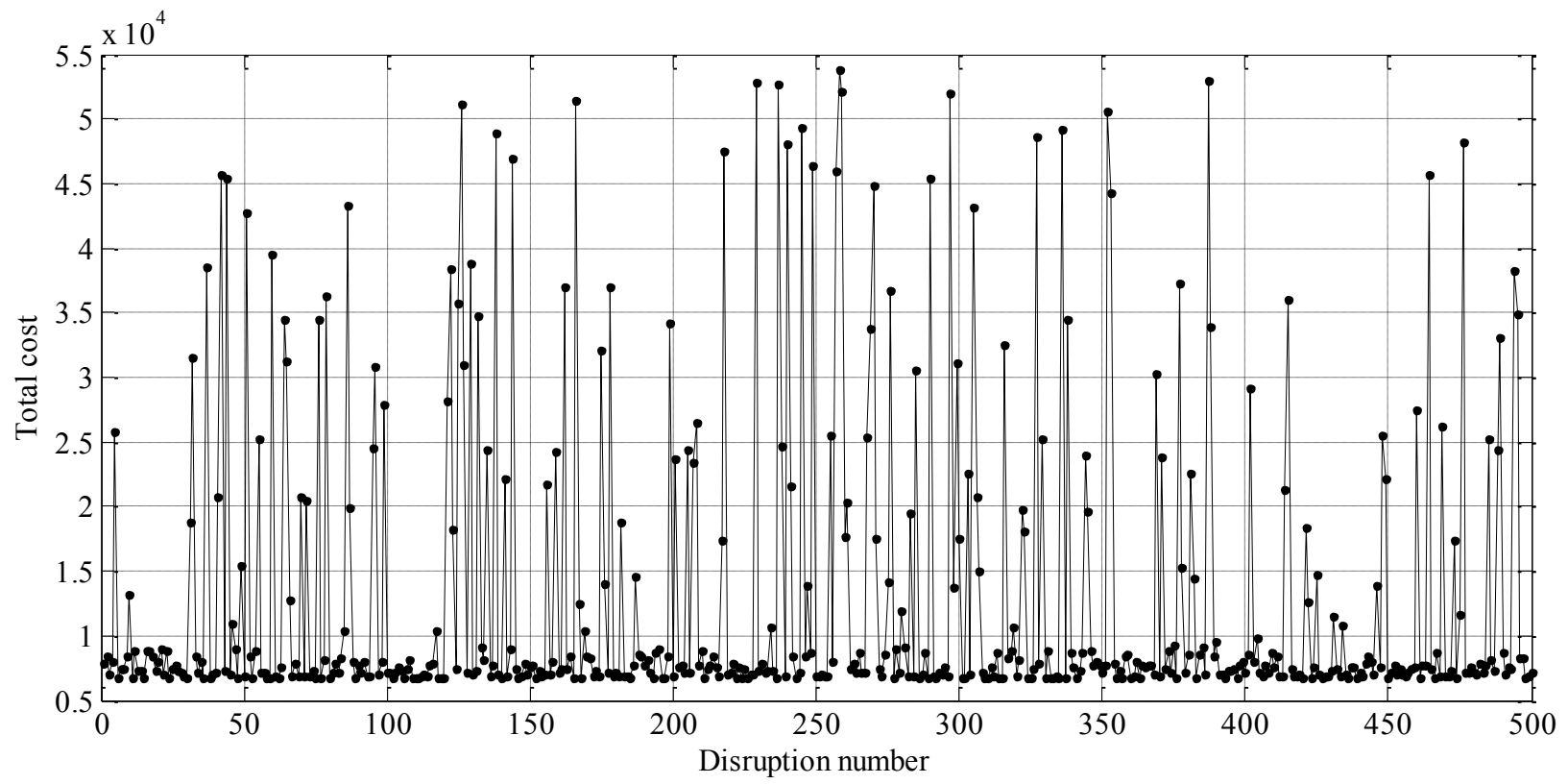

Fig. 5: Total cost vs. disruption number for disruption of raw material 2

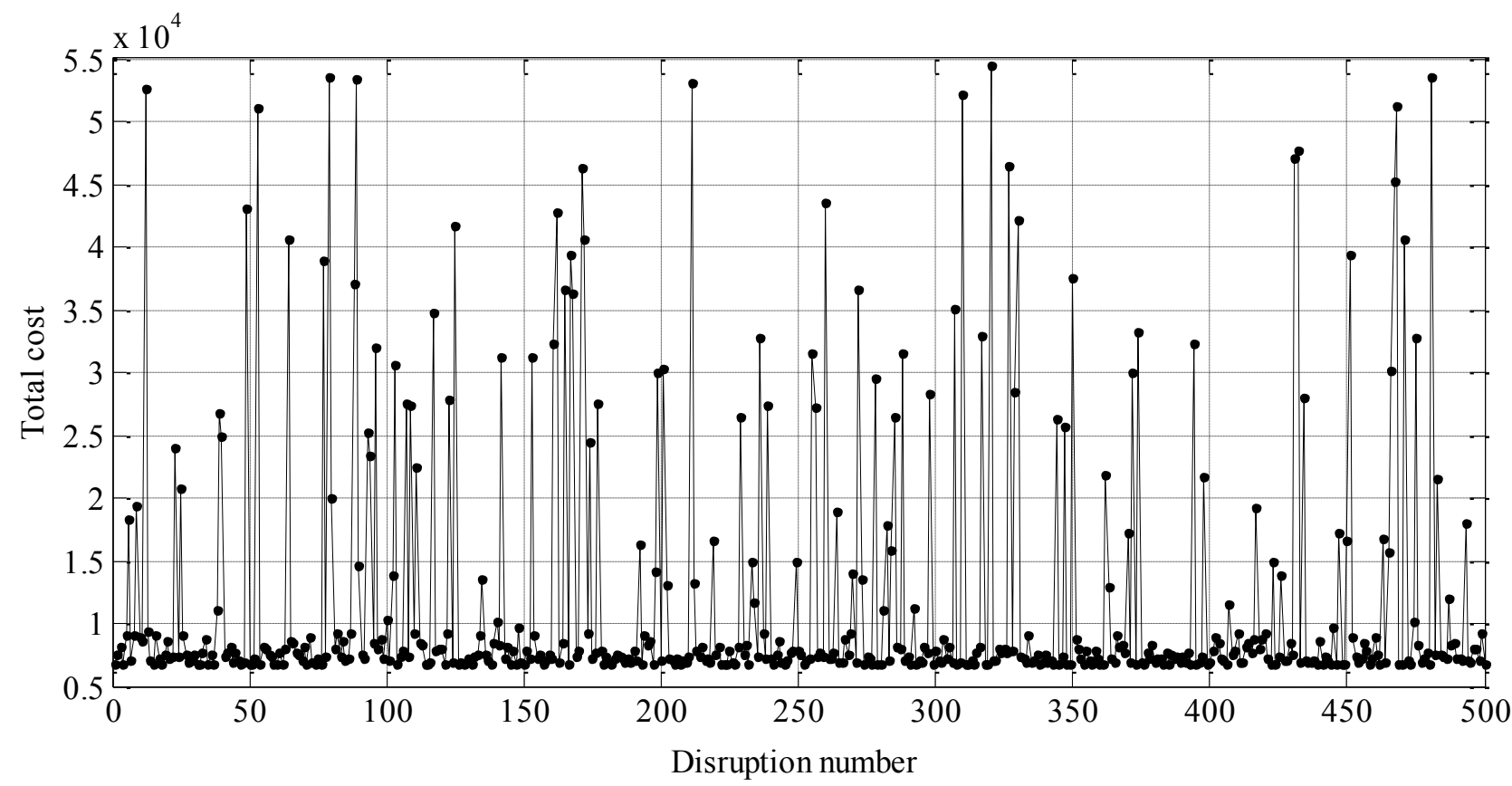

Fig. 6: Total cost vs. disruption number for disruption of raw material 3

We also generated 500 random scenarios for the duration of a supply disruption, for disruption of raw material 2 and 3, using an exponential distribution within the range of $[0.0001,1]$, and the total cost patterns are presented in Figures 5 and 6 respectively. We determined that the mean and 
standard deviation values of the total cost were 13.0800 and 11.4840 thousand respectively, and the maximum and minimum values were 53.8530 and 6.7044 thousand respectively for disruption of raw material 2 and those values were 12.0260, 10.4250, 54.4580 and 6.7009 thousands respectively for disruption of raw material 3.

\subsection{Simulation results}

We ran the simulation model presented in Section 4.2 to experiment with the supply chain disruption scenarios that are close to a real-world process. In real-life cases, disruptions can happen at any time for any raw-material. To make the experiment useful, we generated 2000 random test problems for different disruption scenarios. In the test problems, the supply disruption durations were generated using an exponential distribution, and a histogram of the disruption duration is presented in Figure 7. According to the figure, it is highly likely that disruption will happen for shorter time duration and is less likely for longer time duration. The different costs patterns for random disruption occurrences over the 2000 random scenarios are presented in Figure 8. We calculated the mean, standard deviation, maximum and minimum values of different costs, and they are presented in Table 3 . It is clear that, the model is capable of solving the problem for any type of disruption occurrence. We observed that the both back orders and lost sales costs are present in the solutions and the lost sales costs are significantly greater than the back orders costs. In the simulation results, the maximum back orders cost was 2.9037 thousands, in compare to maximum lost sales cost 44.707 thousands. This is because sometimes, when disruption duration is high, the system is not capable to recover by using only back orders and in those situations, lost sales exist in the solution. We also observed the minimum cost of both back orders and lost sales is 0 . This is because sometimes, when disruption duration is quite low, the system is capable to recover by using the idle time in first recovery cycle and also using only the back orders option. Due to variation in the back orders and lost sales costs, we found that the total cost varied from 6.7012 to 54.3960 thousands with mean 12.437 thousands and standard deviation 11.2020 thousands. This variation is because of the variation in disruption parameters. 


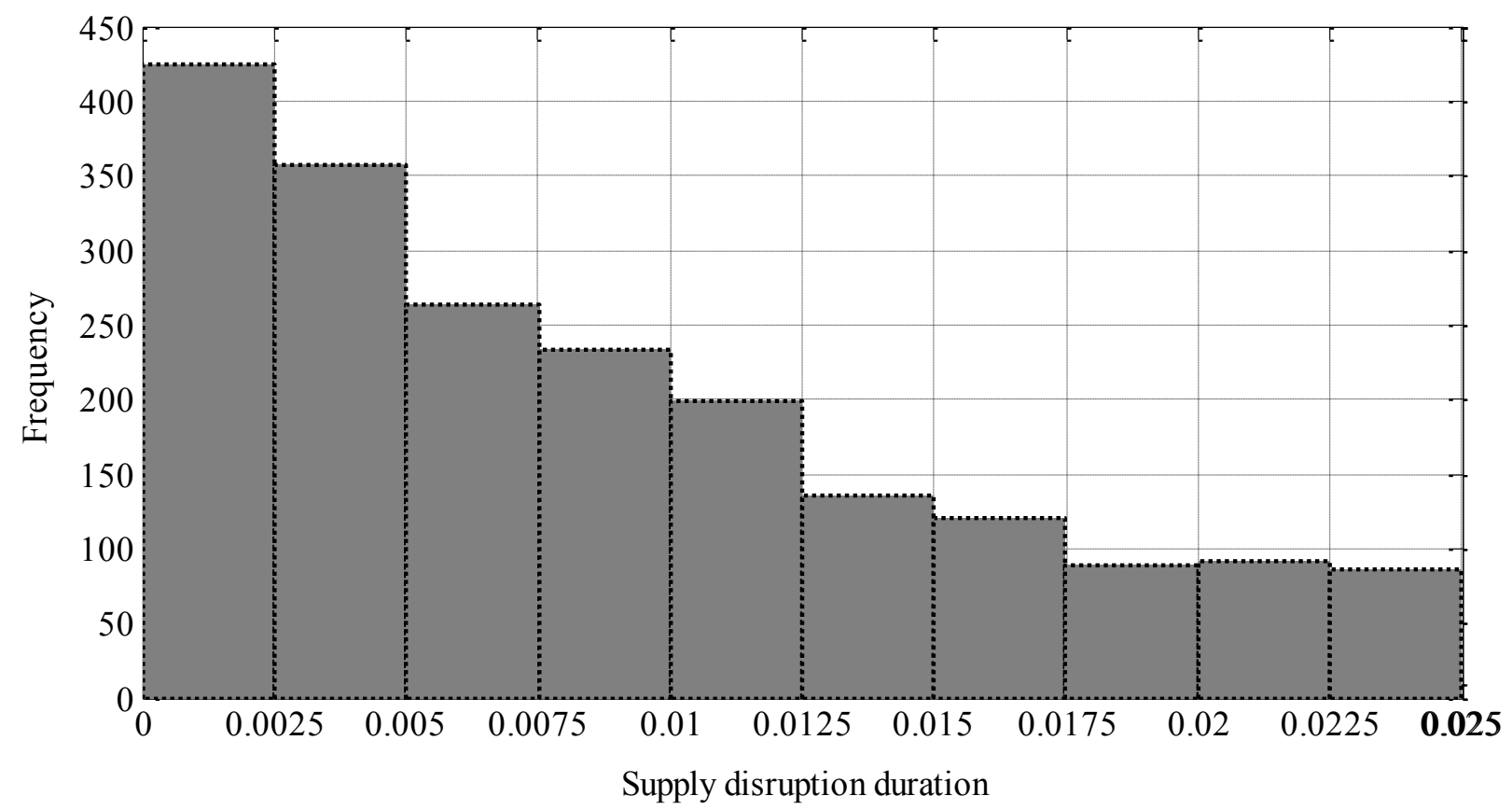

Fig. 7: Histogram of disruption duration for the simulation

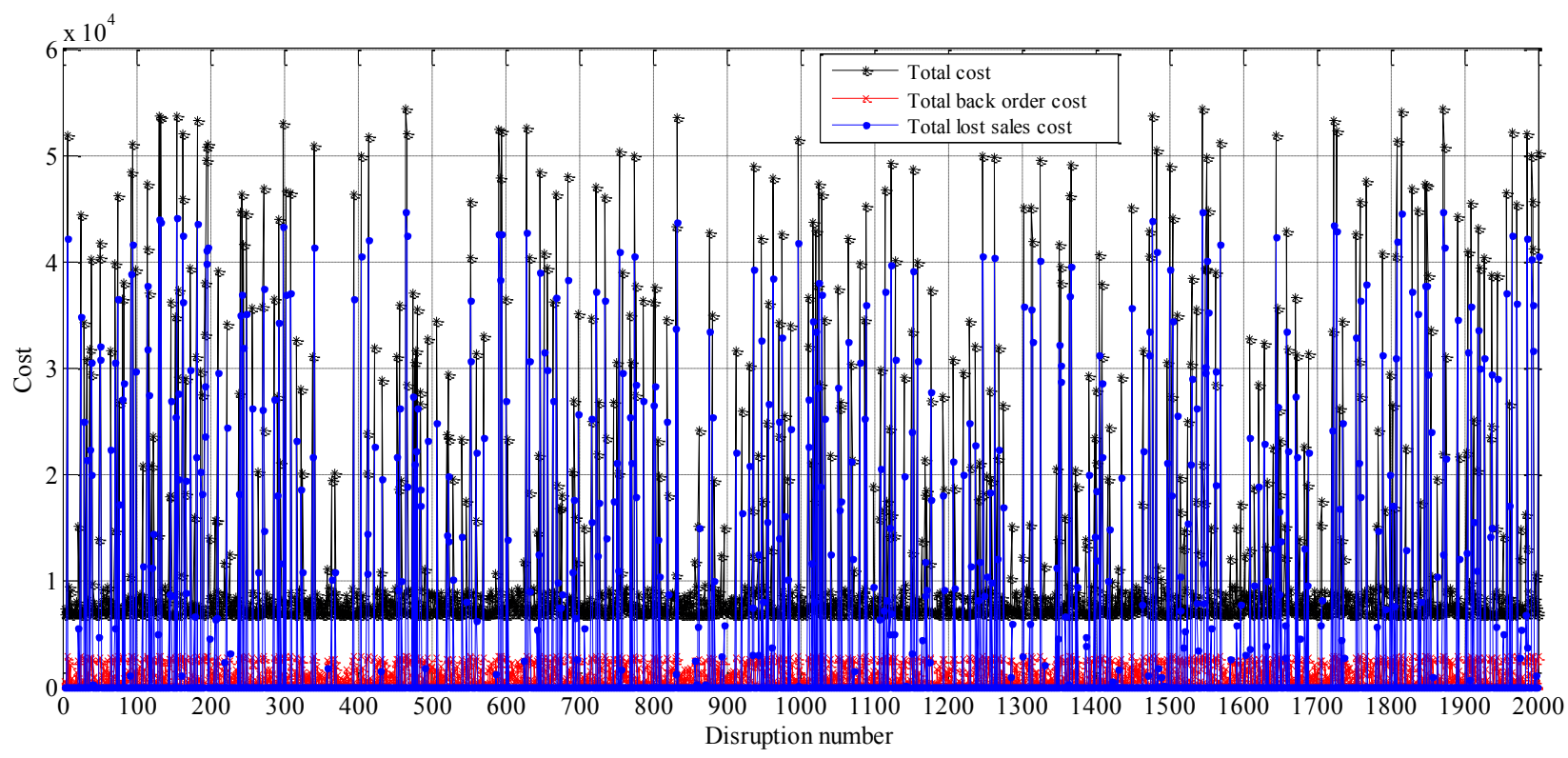

Fig. 8: Simulation results of different costs for 2000 runs

Table 3: Statistic of different costs for the simulation run

\begin{tabular}{|c|c|c|c|c|}
\hline Cost type & $\begin{array}{c}\text { Mean } \\
\text { (Thousands) }\end{array}$ & $\begin{array}{c}\text { Standard deviation } \\
\text { (Thousands) }\end{array}$ & $\begin{array}{c}\text { Maximum } \\
\text { (Thousands) }\end{array}$ & $\begin{array}{c}\text { Minimum } \\
\text { (Thousands) }\end{array}$ \\
\hline $\begin{array}{c}\text { Total back } \\
\text { orders cost }\end{array}$ & 1.0936 & 1.0005 & 2.9037 & 0 \\
\hline $\begin{array}{c}\text { Total lost } \\
\text { sales cost }\end{array}$ & 4.5365 & 10.4750 & 44.7070 & 0 \\
\hline Total cost & 12.4370 & 11.2020 & 54.3960 & 6.7012 \\
\hline
\end{tabular}




\subsection{Recovery plans for a series of disruptions}

To demonstrate the usefulness of our proposed heuristic for solving different scenarios with a series of disruptions, one after another, over a period of time, we used the basic data of the single disruption problem presented in Sections 5.1 and 5.2. The first disruption can be solved by using the heuristic developed for a single disruption. Then, if another disruption occurs after the recovery window of a previous one, it could be considered another single disruption that would not affect the revised plan based on the previous disruption. However, as a new disruption within the recovery window of any previous one may affect the previous revised plan, the revised plan for its recovery window must be considered as a set of additional restrictions. For experimental purposes, we randomly generated a series of ten dependent disruptions, one after another, as shown in Table 4. Although they could happen continuously, we present only ten as a sample representation.

Table 4: A random case for a series of disruptions

\begin{tabular}{|c|c|c|c|}
\hline $\begin{array}{c}\text { Disruption } \\
\text { number }\end{array}$ & $\begin{array}{c}\text { Disrupted raw } \\
\text { material }\end{array}$ & $\begin{array}{c}\text { Disrupted cycle } \\
\text { number }\end{array}$ & Disruption duration \\
\hline 1 & 2 & -- & 0.009 \\
\hline 2 & 3 & 4 & 0.016 \\
\hline 3 & 1 & 6 & 0.012 \\
\hline 4 & 3 & 8 & 0.007 \\
\hline 5 & 3 & 2 & 0.014 \\
\hline 6 & 2 & 8 & 0.020 \\
\hline 7 & 1 & 3 & 0.006 \\
\hline 8 & 1 & 5 & 0.022 \\
\hline 9 & 2 & 7 & 0.013 \\
\hline 10 & 3 & 4 & 0.018 \\
\hline--- & --- & --- & -- \\
\hline
\end{tabular}

To minimize the total cost in the system, the supply, production and delivery quantities were revised immediately, after each disruption took place, for the next five cycles. The problem was then solved using the proposed heuristic for multiple disruptions, as presented in Section 4.3, with the results recorded after each disruption, the total lost sales cost, total back orders cost and total cost are shown in Table 5. We observed that the back orders costs are always present in the solution for all disruptions. This is because the system utilizes the idle time in the recovery time window for every disruption, but varied due to having variation in disruption parameters. We also observed that there was no lost sales cost for disruption number 1, 3, 4 and 9. This is because the system is capable to recover by using only back orders option. In case of disruption number $2,5,7,8$ and 10 , the new 
disruption occurred within the recovery window of previous disruption. In this situation the effect of both previous and current disruptions was taken into consideration to obtain the recovery plan. We observed that lost sales costs are quite higher in these situations. The lost sales costs can also be higher with longer disruption duration (such as for disruption number 6 in Table 5).

Table 5: Results for the series of disruptions

\begin{tabular}{|c|c|c|c|}
\hline $\begin{array}{c}\text { Disruption } \\
\text { number }\end{array}$ & Total back orders & Total lost sales & Total cost \\
\hline 1 & $1,105.22$ & 0 & $7,892.47$ \\
\hline 2 & $2,503.01$ & $8,790.60$ & $18,167.13$ \\
\hline 3 & $1,871.36$ & 0 & $8,846.95$ \\
\hline 4 & 715.29 & 0 & $7,548.71$ \\
\hline 5 & $2,481.99$ & $6,706.85$ & $16,071.98$ \\
\hline 6 & $2,672.56$ & $24,790.60$ & $34,112.44$ \\
\hline 7 & $2,574.09$ & $15,664.97$ & $25,198.68$ \\
\hline 8 & $2,949.74$ & $48,455.57$ & $58,357.03$ \\
\hline 9 & $2,171.73$ & 0 & $8,971.95$ \\
\hline 10 & $2,670.71$ & $24,623.09$ & $34,110.28$ \\
\hline--- & --- & -- & -- \\
\hline
\end{tabular}

To compare and judge the heuristic solutions of the multiple disruptions, we have also developed another solution approach for multiple disruptions by using the PS technique. Then we compared the solutions of 30 randomly generated test problems. The comparison showed that the average percentage of deviation was only the negligible amount of $0.000008 \%$. So our heuristic is also capable of handling multiple disruptions on a real-time basis.

\section{Conclusions}

The main objective of this paper was to develop a reactive mitigation approach to recover from supply disruptions in a three-tier supply chain system. A new mathematical and heuristic approach was developed for managing a single supply disruption after its occurrence. Then the mathematical model and the heuristic were extended to develop a dynamic approach for managing multiple supply disruptions, after the occurrence of each disruption, on a real-time basis. These heuristics were validated by comparing the results from another standard solution technique which showed that the average percentage of deviation was a negligible amount for a good number of randomly generated 
test problems. A large set of random experiments was performed to analyze the characteristics of the developed models, and finally, a simulation model was developed to enable solving the supply disruption problem as a real-world process and found that the proposed mathematical and heuristic approach can be implemented to solve the real-world supply disruption problems.

The proposed approach offers a potentially very useful quantitative approach to help decision makers to make prompt and accurate decisions on a real-time recovery plan, whenever a sudden, or a series of supply disruptions, takes place in a three-tier supply chain system. Decision maker can make a suitable decision very easily because our proposed approach is capable to present the recovery plan with different decision variables and different costs data. The supply chain system can return to its normal supply, production and delivery plan as quickly as possible after a supply disruption with the help of this approach, and thereby minimize its total costs and enhance its reputation.

In real-life, a supply chain system may contain more than three tiers with any number of nodes at any tier. The disruption may occur at any node that includes all supply, production, and delivery activities. The extension of the current research to investigate all these aspects will make it a robust approach for a wide range of practical supply chain scenarios. Additionally, it would be worthwhile to incorporate environmental aspects, such as lowering supply chain costs by reducing travel distances, carbon emission, production costs, product waste, and unplanned activities. Another interesting extension would be to relax the assumption of a single type of item, so as to consider multiple types of items, as well as to analyze the impacts of disruptions on different types of items in a multi-tier supply chain system. In addition, several aspects could be introduced into the developed model, such as:

i. Considering safety-stock level and analyzing the effect of disruption on safety stock, and determining the optimum level to minimize the effect of a disruption.

ii. Considering lead time factors and analyzing the effect of disruption on lead time and disruption recovery.

\section{References}

Agnetis, A. et al., 2001. Set-Up Coordination between Two Stages of a Supply. Annals of Operations Research, 107, pp.15-32.

Bai, X. \& Liu, Y., 2014. Robust optimization of supply chain network design in fuzzy decision system. Journal of Intelligent Manufacturing, p.in press. 
Bottani, E. \& Montanari, R., 2010. Supply chain design and cost analysis through simulation. International Journal of Production Research, 48(10), pp.2859-2886.

Choi, T.-M., Yeung, W.-K. \& Cheng, T.C.E., 2013. Scheduling and co-ordination of multi-suppliers single-warehouse-operator single-manufacturer supply chains with variable production rates and storage costs. International Journal of Production Research, 51(9), pp.2593-2601.

Chopra, S., Reinhardt, G. \& Mohan, U., 2007. The Importance of Decoupling Recurrent and Disruption Risks in a Supply Chain. Naval Research Logistics, 54(5), pp.544-555.

Eisenstein, D.D., 2005. Recovering Cyclic Schedules Using Dynamic Produce-Up-To Policies. Operations Research, 53(4), pp.675-688.

Hishamuddin, H., Sarker, R.A. \& Essam, D., 2012. A disruption recovery model for a single stage production-inventory system. European Journal of Operational Research, 222(3), pp.464-473.

Hishamuddin, H., Sarker, R.A. \& Essam, D., 2014. A recovery mechanism for a two echelon supply chain system under supply disruption. Economic Modelling, 38, pp.555-563.

Hishamuddin, H., Sarker, R.A. \& Essam, D., 2013. A recovery model for a two-echelon serial supply chain with consideration of transportation disruption. Computers \& Industrial Engineering, 64(2), pp.552-561.

Hou, J., Zeng, A.Z. \& Zhao, L., 2010. Coordination with a backup supplier through buy-back contract under supply disruption. Transportation Research Part E: Logistics and Transportation Review, 46(6), pp.881-895.

Hu, F. et al., 2013. Coordination in a Single-Retailer Two-Supplier Supply Chain under Random Demand and Random Supply with Disruption. Discrete Dynamics in Nature and Society, 2013, pp.1-12.

Kogan, K. \& Tapiero, C.S., 2012. Coordination of co-investments in supply chain infrastructure. Journal of Intelligent Manufacturing, 23(6), pp.2471-2475.

Li, J., Wang, S. \& Cheng, T.C.E., 2010. Competition and cooperation in a single-retailer twosupplier supply chain with supply disruption. International Journal of Production Economics, 124(1), pp.137-150.

Li, Z., Xu, S.H. \& Hayya, J., 2004. A Periodic-Review Inventory System With Supply Interruptions. Probability in the Engineering and Informational Sciences, 18(1), pp.33-53. 
Masud, M.A.A., Paul, S.K. \& Azeem, A., 2014. Optimisation of a production inventory model with reliability considerations. International Journal of Logistics Systems and Management, 17(1), pp.22-45.

Mohebbi, E., 2004. A replenishment model for the supply-uncertainty problem. International Journal of Production Economics, 87(1), pp.25-37.

Mohebbi, E. \& Hao, D., 2008. An inventory model with non-resuming randomly interruptible lead time. International Journal of Production Economics, 114(2), pp.755-768.

Özekici, S. \& Parlar, M., 1999. Inventory models with unreliable suppliers in a random environment. Annals of Operations Research, 91, pp.123-136.

Pal, B., Sana, S.S. \& Chaudhuri, K., 2014. A multi-echelon production-inventory system with supply disruption. Journal of Manufacturing Systems, 33(2), pp.262-276.

Pal, B., Sana, S.S. \& Chaudhuri, K., 2012a. A multi-echelon supply chain model for reworkable items in multiple-markets with supply disruption. Economic Modelling, 29(5), pp.1891-1898.

Pal, B., Sana, S.S. \& Chaudhuri, K., 2012b. A three layer multi-item production-inventory model for multiple suppliers and retailers. Economic Modelling, 29(6), pp.2704-2710.

Park, Y., Hong, P. \& Roh, J.J., 2013. Supply chain lessons from the catastrophic natural disaster in Japan. Business Horizons, 56(1), pp.75-85.

Parlar, M. \& Berkin, D., 1991. Future supply uncertainty in EOQ models. Naval Research Logistics, 38(1), pp.107-121.

Parlar, M. \& Perry, D., 1996. Inventory models of future supply uncertainty with single and multiple suppliers. Naval Research Logistics, 43(2), pp.191-210.

Paul, S.K., Azeem, A., et al., 2014. Development of a production inventory model with uncertainty and reliability considerations. Optimization and Engineering, 15(3), pp.697-720.

Paul, S.K., Sarker, R. \& Daryl, D., 2016. Managing risk and disruption in production-inventory and supply chain systems: a review. Journal of Industrial and Management Optimization, 12(3), pp.1009-1029.

Paul, S.K., Sarker, R. \& Essam, D., 2013. A Disruption Recovery Model in a Production-Inventory System with Demand Uncertainty and Process Reliability. Lecture notes in computer science, 8104, pp.511-522. 
Paul, S.K., Sarker, R. \& Essam, D., 2015a. A disruption recovery plan in a three-stage productioninventory system. Computers and Operations Research, 57, pp.60-72.

Paul, S.K., Sarker, R. \& Essam, D., 2015b. Managing disruption in an imperfect productioninventory system. Computers \& Industrial Engineering, 84, pp.101-112.

Paul, S.K., Sarker, R. \& Essam, D., 2014a. Managing real-time demand fluctuation under a supplierretailer coordinated system. International Journal of Production Economics, 158, pp.231-243.

Paul, S.K., Sarker, R. \& Essam, D., 2014b. Managing Supply Disruption in a Three-Tier Supply Chain with Multiple Suppliers and Retailers. In 2014 IEEE International Conference on Industrial Engineering and Engineering Management (IEEM). Selangor, Malaysia, pp. 194198.

Paul, S.K., Sarker, R. \& Essam, D., 2014c. Real time disruption management for a two-stage batch production-inventory system with reliability considerations. European Journal of Operational Research, 237(1), pp.113-128.

Petridis, K., 2013. Optimal design of multi-echelon supply chain networks under normally distributed demand. Annals of Operations Research, (In press), pp.1-29. Available at: http://link.springer.com/10.1007/s10479-013-1420-6 [Accessed November 30, 2014].

Petrovic, D. et al., 2008. Coordinated control of distribution supply chains in the presence of fuzzy customer demand. European Journal of Operational Research, 185(1), pp.146-158.

Qi, L., 2013. A continuous-review inventory model with random disruptions at the primary supplier. European Journal of Operational Research, 225(1), pp.59-74.

Qi, L., Shen, Z.J.M. \& Snyder, L. V., 2010. The Effect of Supply Disruptions on Supply Chain Design Decisions. Transportation Science, 44(2), pp.274-289.

Ray, P. \& Jenamani, M., 2014. Sourcing decision under disruption risk with supply and demand uncertainty: A newsvendor approach. Annals of Operations Research, (In press), pp.1-26.

Sana, S.S., 2012. A collaborating inventory model in a supply chain. Economic Modelling, 29(5), pp.2016-2023.

Sana, S.S., 2011. A production-inventory model of imperfect quality products in a three-layer supply chain. Decision Support Systems, 50(2), pp.539-547. 
Schmitt, A.J., Snyder, L. V. \& Shen, Z.J.M., 2010. Inventory systems with stochastic demand and supply: Properties and approximations. European Journal of Operational Research, 206(2), pp.313-328.

Shao, X.-F. \& Dong, M., 2012. Supply Disruption and Reactive Strategies in an Assemble-to-Order Supply Chain With Time-Sensitive Demand. IEEE Transactions on Engineering Management, 59(2), pp.201-212.

Snyder, L. V., 2014. A tight approximation for an EOQ model with supply disruptions. International Journal of Production Economics, 155, pp.91-108.

Sodhi, M.S. \& Chopra, S., 2004. Managing risk to avoid supply-chain breakdown. MIT Sloan Management Review, 46(1), pp.53-61.

Supply Chain Resilience Report, 2011. Supply chain resilience (3rd annual survey), The Business Continuity Institute. Available at: http://www.cips.org/Documents/Resources/Knowledge Summary/BCI Supply Chain Resilience 2011 Public Version.pdf.

Tang, L.C. \& Lee, L.H., 2005. A simple recovery strategy for economic lot scheduling problem: A two-product case. International Journal of Production Economics, 98(1), pp.97-107.

Tomlin, B., 2006. On the Value of Mitigation and Contingency Strategies for Managing Supply Chain Disruption Risks. Management Science, 52(5), pp.639-657.

Weiss, H.J. \& Rosenthal, E.C., 1992. Optimal ordering policies when anticipating a disruption in supply or demand. European Journal of Operational Research, 59(3), pp.370-382.

Xia, Y. et al., 2004. Real-time disruption management in a two-stage production and inventory system. IIE Transactions, 36(2), pp.111-125.

Xu, R. \& Zhai, X., 2010. Manufacturer's coordination mechanism for single-period supply chain problems with fuzzy demand. Mathematical and Computer Modelling, 51(5-6), pp.693-699.

Xu, X. \& Meng, Z., 2014. Coordination between a supplier and a retailer in terms of profit concession for a two-stage supply chain. International Journal of Production Research, 52(7), pp.2122-2133.

Yan, X. et al., 2014. Optimal ordering policies and sourcing strategies with supply disruption. Journal of Industrial and Management Optimization, 10(4), pp.1147-1168. 
Yang, J., Qi, X. \& Yu, G., 2005. Disruption management in production planning. Naval Research Logistics, 52(5), pp.420-442.

Zhang, D. et al., 2013. A study of emergency management of supply chain under supply disruption. Neural Computing and Applications, 24(1), pp.13-20.

Zhou, C., Zhao, R. \& Tang, W., 2008. Two-echelon supply chain games in a fuzzy environment. Computers \& Industrial Engineering, 55(2), pp.390-405.

\section{Appendix A}

Parameters of PS technique

In the proposed PS based solution approach, following PS parameters are used to solve the model.

Maximum number of iterations: $100 *$ Number of variables

Polling order: Random

X tolerance: $1 \mathrm{e}-8$

Function tolerance: $1 \mathrm{e}-8$

Non-linear constraint tolerance: 1e-8

Cache tolerance: $1 \mathrm{e}-8$

Search method: Latin hypercube

Maximum function evaluations: $10^{6}$

Other parameters are set as the default in the optimization toolbox of MATLAB R2012a. 
Appendix B

Table B.1: Revised plans for disruption instances 1 and 2

\begin{tabular}{|c|c|c|c|c|c|c|}
\hline Disruption instance & \multicolumn{6}{|c|}{ Revised plan } \\
\hline \multirow{14}{*}{1} & \multicolumn{6}{|c|}{ Revised raw material supply plan } \\
\hline & Supplier & $X_{1 i}$ & $X_{2 i}$ & $X_{3 i}$ & $X_{4 i}$ & $X_{5 i}$ \\
\hline & 1 & 2689.6 & 2689.6 & 2689.6 & 2689.6 & 2689.6 \\
\hline & 2 & 8068.8 & 8068.8 & 8068.8 & 8068.8 & 8068.8 \\
\hline & 3 & 5379.2 & 5379.2 & 5379.2 & 5379.2 & 5379.2 \\
\hline & \multicolumn{6}{|c|}{ Revised production plan } \\
\hline & $Y_{1}$ & \multicolumn{2}{|c|}{$Y_{2}$} & \begin{tabular}{l|l}
$Y_{3}$ & \\
\end{tabular} & $Y_{4}$ & $Y_{5}$ \\
\hline & \multirow[t]{2}{*}{2689.6} & \multicolumn{2}{|c|}{2689.6} & \begin{tabular}{l|l}
2689.6 &
\end{tabular} & 2689.6 & 2689.6 \\
\hline & & \multicolumn{5}{|c|}{ Revised delivery plan } \\
\hline & Retailer & $Z_{1 j}$ & $Z_{2 j}$ & $Z_{3 j}$ & $Z_{4 j}$ & $Z_{5 j}$ \\
\hline & 1 & 448.3 & 448.3 & 448.3 & 448.3 & 448.3 \\
\hline & 2 & 747.1 & 747.1 & 747.1 & 747.1 & 747.1 \\
\hline & 3 & 597.7 & 597.7 & 597.7 & 597.7 & 597.7 \\
\hline & 4 & 896.5 & 896.5 & 896.5 & 896.5 & 896.5 \\
\hline \multirow{14}{*}{2} & & & sed raw & 1 supply & & \\
\hline & Supplier & $X_{1 i}$ & $X_{2 i}$ & $X_{3 i}$ & $X_{4 i}$ & $X_{5 i}$ \\
\hline & 1 & 2689.6 & 2069.9 & 2689.6 & 2689.6 & 2689.6 \\
\hline & 2 & 8068.8 & 6209.6 & 8068.8 & 8068.8 & 8068.8 \\
\hline & 3 & 5379.2 & 4139.7 & 5379.2 & 5379.2 & 5379.2 \\
\hline & & & Revised & tion plan & & \\
\hline & $Y_{1}$ & $Y_{2}$ & & & $Y_{4}$ & $Y_{5}$ \\
\hline & 2689.6 & 2069 & & & 2689.6 & 2689.6 \\
\hline & & & Revisec & ry plan & & \\
\hline & Retailer & $Z_{1 j}$ & $Z_{2 j}$ & $Z_{3 j}$ & $Z_{4 j}$ & $Z_{5 j}$ \\
\hline & 1 & 448.3 & 345.0 & 448.3 & 448.3 & 448.3 \\
\hline & 2 & 747.1 & 575.0 & 747.1 & 747.1 & 747.1 \\
\hline & 3 & 597.7 & 460.0 & 597.7 & 597.7 & 597.7 \\
\hline & 4 & 896.5 & 690.0 & 896.5 & 896.5 & 896.5 \\
\hline
\end{tabular}

